\title{
Emergency Incident Management: An Evolving Incident Control System Framework
}

\author{
Ian Dwyer and Christine Owen \\ Bushfire Co-operative Research Centre, University of Tasmania, Australia
}

\begin{abstract}
This article reports on an investigation into the use of Incident Control Systems (e.g., AlIMS/ CIMS) by personnel involved in emergency incident management in fire and emergency services agencies in Australia and New Zealand. A questionnaire was distributed that aimed to assess how information flowed between emergency incident management personnel at different layers of the incident control system, and what enabled and constrained coordination between those personnel. Data were collected from personnel on the fire or incident ground; members of Incident Management Teams; as well as staff operating in regional and state centres of coordination. To date there have been 579 responses spread across 24 agencies. The findings reveal that while there is a high level of satisfaction with overall organisational arrangements and reporting relationships, there are some systemic tensions in, and dissatisfaction evident with, communication arrangements. The extent to which Incident Control Systems facilitate the organisational flexibility needed during dynamic and often unpredictable situations is also discussed. Where appropriate, comparisons are made with similar questionnaire data collected in 2003 by AFAC (Australasian Fire Authorities Council).
\end{abstract}

Keywords: incident control systems, bushfire, organisational response

For countries in the Pacific and on the Pacific Rim, the threat of natural disasters and potential catastrophe is always present. Consequently, organising for emergency incident management frequently involves responding to events such as cyclones, floods, bushfires and earthquakes. Such emergency incidents not only threaten human life and property, but also critical infrastructure (e.g., water catchments and power stations), important commercial industries (e.g., the sugar industry) and environmental assets (including unique wildlife and vegetation). Responding to natural disasters is the province of a range of agencies with fire and emergency services responsibilities. These agencies need to successfully manage the threat in order to mitigate the community impact of an emergency. Left unmanaged, even a relatively small-scale emergency event has the potential to turn into a disaster, or 'unexpected event that exceeds the normal capacity of a community to respond to adverse events' (Comfort, Ko \& Zagorecki, 2004, p. 298).

Central to managing such potentially large, complex, temporally challenging, and dangerous incidents in Australia and New Zealand is the Australasian Interservice Incident Management System (AIIMS), as it is known in Australia, and the Coordinated Incident Management System (CIMS), as it is known in New Zealand. Both systems are based on work conducted in the 1980s in the United States where the National Incident Management System or NIMS was developed (DHS, 2008). The Australian and New Zealand systems are based on NIMS principles and are designed to operate effectively for any type of incident (AFAC, 2005). For the purposes of this article AIIMS and CIMS will be referred to as Incident Control Systems (ICS).

ICS are underpinned by three key principles; namely, management by objectives (all personnel involved in the incident work from a common set of objectives and complementary Incident Action Plans for achieving those objectives); functional management (which includes utilisation of four specific functions (control, planning, operations, and logistics) within the Incident Management Teams tasked with managing the incident); and, span of control (within ICS structures, as an incident escalates, a supervising officer's span of control should not exceed five reporting groups) (AFAC, 2005).

To date, both the Australian and New Zealand systems have been used mainly by agencies with fire and

Address for correspondence: Dr Christine Owen, Bushfire Co-operative Research Centre, University of Tasmania, Private Bag 66, Hobart, TAS 7001. E-mail: Christine.Owen@utas.edu.au 
land management responsibilities as well as emergency services agencies responsible for natural disasters. Accordingly, this article focuses on understanding what personnel using ICS thought of the emergency incident management processes in place, and in particular, the extent to which such systems enabled or constrained successful information flow, coordination between layers in the system, and ultimately, the organisational flexibility that may be needed in volatile, unpredictable situations (Bigley \& Roberts, 2001; Mendonca \& Wallace, 2006).

\section{Purpose of the Paper}

The main purpose of this article then, is to report on findings that address the following research questions:

1. To what degree are the practices embedded within Incident Control Systems to support information flow and coordination being used by personnel engaged in emergency incident management, and in particular, how have these evolved since 2003?

2. How satisfied are personnel with those systems, and are there any systemic areas of concern evident?

3. To what degree does the existing Incident Control System enable or constrain the organisational flexibility needed in dynamic, unpredictable incidents?

\section{Context for the Study}

Modern fire and emergency services not only face ever more complex, unpredictable and often hazardous working conditions, but are expected to successfully manage their operations within an increasingly unforgiving social, political and economic climate (Bigley \& Roberts, 2001). Operational failures resulting from 'inappropriate, incomplete, laggardly, or otherwise mindless organisational responses' (ibid., p. 1281) are no longer acceptable. Rapidly changing situations often mean that emergency services organisations need to be highly flexible if they are to have any hope of achieving consistently safe, high-performance outcomes (Bigley \& Roberts, 2001; Weick \& Sutcliffe, 2001; Wilson, Burke, Priest \& Salas, 2005).

To help highlight some of the challenges emergency services agencies might face, it is useful to consider the example of the 2006/2007 Victorian bushfires - where at one point there were 83 fires burning from a drylightning storm that had crossed the state. Weather conditions resulted in many of these fires coalescing into a series of much larger-scale fires, which became known as the 'Great Divide Complex'. A 10-week 'campaign' fire-fighting effort ensued as the fires burned over 1 million hectares of land. During this time, 47 communities were directly threatened, as well as four water catchments and dams, seven power generation stations, three coal mines, three gas production facilities, six gas pipelines and six electricity transmission lines servicing the Eastern Seaboard of Australia (Owen, Hickey \& Douglas, 2008)

Responding to fires of such magnitude means that personnel require an awareness of the conditions, the tactics and strategy of the operational effort, as well as how/where resources are being deployed. In the example above, over 20,500 people (paid and volunteer) were called upon to work on the fires, including personnel in seven Incident Management Teams, two regional coordinating centres, and a State-level Emergency Coordination Centre. Clearly it is crucial during large operations like this that there is effective information flow and coordination within and between agencies and teams of people (DHS, 2008; Militello, Patterson, Bowman, \& Wears, 2007), and that the organisations involved can be sufficiently flexible to quickly adjust to the demands of their environments (Moynihan \& La Follette, 2007; Wise, 2006). This is because such incidents are obviously complex, highly dynamic, and have no spatial or temporal order (i.e., both the area covered by the fire and the speed of its movement are constantly changing and unpredictable) (Mendonca \& Wallace, 2006; Weick \& Sutcliffe, 2001).

The challenges facing personnel working on these sorts of incidents are therefore multifaceted. Effective incident management organising must be structured in ways that allow people to effectively share what they know, coordinate their activities/responses, and adjust to the conditions in a way that is both dynamic and suitably responsive. Therefore, a first issue pertinent to this article is the extent to which the ICS enables/supports or constrains their capacity to do so.

The desirability of having organisational systems that support effective communication and information flow within and between agencies has been widely appreciated in the literature, and reports of the failure of such systems in major international emergency events has been well documented (Lutz \& Lindell, 2008; Militello, Patterson, Bowman \& Wears, 2007; The 9/11 Commission, 2004). Militello, Patterson, Bowman and Wears (2007) for instance, noted ' $[t]$ he amount of information sharing that must happen within and outside of the EOC [Emergency Operations Center] is quite daunting' (p. 28); while The 9/11 Commission (2004) in one of their key recommendations proposed that during future large scale emergency incident management events 'information be shared horizontally, across new networks that transcend individual agencies' (p. 418).

Accordingly, the question of how to enable effective coordination between layers in a complex organisational effort (as well as between different stakeholders in the event) is a second important issue pertinent to this article - particularly when, as mentioned above, many differentiated layers start developing within an expanding ICS (e.g., between the fire-ground, Incident Management Teams, and coordination centres). Again, 
to help understand where some of the major information flow and coordination issues may arise, it is useful to consider how an ICS charged with managing a bushfire may evolve in terms of its organisational hierarchies as the fire(s) spread.

When a fire ignition occurs, the initial response involves fire-fighters, officers in charge of fire appliances and crew leaders attending the fire-ground in an effort to extinguish the fire. As the fire increases in size, firefighting personnel are divided into Sectors, which may in turn become Divisions - all of which need to coordinate their activities. At this level of complexity, activities on the fireground are then supported by an Incident Management Team, which is established away from the fire-ground.

The Incident Management Team is tasked with effectively and efficiently controlling the incident in terms of planning, resourcing, personnel wellbeing, and community/environmental impact (AFAC, 2005). Within the Incident Management Team there is also a need for coordination between people performing the various functions; namely, operations (tasked with taking responsibility for operational resources and personnel); planning (tasked with taking responsibility for planning strategies and resource and incident information management); and logistics (tasked with taking responsibility for managing logistical activities and resources) (AFAC, 2005).

Typically orchestrating the response is an Incident Controller (and sometimes a Deputy) who, in addition to ensuring the Incident Management Team functions effectively, has responsibility for informing/updating: other agencies involved in the response (e.g., police), other stakeholders (e.g., communities through media briefings), other organisations who may be impacted by the event (e.g., critical infrastructure), and local municipalities likely to be affected. If there are multiple fires, as is often the case, the Incident Management Teams may themselves require coordinated support through regional and state levels of coordination.

With so many potential areas for communication, information flow and/or coordination to break down, or at least become suboptimal, it was perhaps hardly surprising that during the response to major incidents such as the large-scale forest fires in the United States during the 1990s, there were a number of significant coordination problems identified that impacted on the effectiveness of the effort. These included: overloaded spans of control, lack of reliable information flow, inadequate and incompatible communications systems, lack of interagency coordination, unclear lines of authority, lack of common terminology among responding agencies, and unclear or unspecified incident objectives (Lutz \& Lindell, 2008). Also noteworthy was that many, if not all of these problems reappeared during the subsequent response to Hurricane Katrina in 2005 (Wise, 2006).

As an ICS expands in the way described above, it is possible to further appreciate why some might argue an
ICS can quickly become bureaucratic and inflexible, and as such, is an approach suitable only for routine operations (Moynihan \& La Follette, 2007). The third and final issue pertinent to this article then is whether ICSbased organisational forms can enable the necessary organisational flexibility ostensibly required as situational volatility and complexity rise (Bigley \& Roberts, 2001; DHS, 2008). Clearly it would be highly undesirable if the ICS actually became a limiting factor in terms of facilitating organisational flexibility as the incident unfolded - a point acknowledged in the DHS (2008) NIMS core policy document: '... flexibility is essential for NIMS to be applicable across the full spectrum of potential incidents, including those that require multiagency, multijurisdictional, ... and/or multidisciplinary coordination' (p. 6).

Of course, ICS advocates claim that the bureaucratic features of those organisational forms, although structured around formalisation and standardisation (AFAC, 2005; DHS, 2008), can facilitate both the steady efficiency needed in less demanding work environments and the flexibility supposedly needed in more complex, dynamic circumstances They reportedly do so by invoking and then building a system of organic, temporary, team-based working arrangements which acknowledge the importance of maintaining explicit forms of communication and coordination processes and systems (DHS, 2008). Thus regardless of application, the overarching aim of the ICS approach is to provide a common management framework with the capacity to allow the core unit of the system, the Incident Management Team, to expand as the incident expands and so attain a degree of reliability and safety across a broad range of working conditions - including those marked by considerable uncertainty and/or risk (Bigley \& Roberts, 2001; DHS, 2008; Moynihan \& La Follette, 2007).

In short, ICS are essentially incident-level frameworks based on the three key principles mentioned earlier, These three principles mean that as an incident grows, so the units managing the incident can scale up or down accordingly (AFAC, 2005). The capacity to scale up or down like this is seen by ICS proponents as critical in enabling successful and flexible incident management work practices and processes (DHS, 2008; Moynihan \& La Follette, 2007; Wise, 2006).

Yet, despite the potentially important function of ICS during emergency incidents, there has been little research into the extent to which organising approaches like AIIMS and/or CIMS: (a) actually enable or constrain peoples' ability to cope with the pressures inherent to uncertain and dynamic situations (Crichton, Lauche \& Flin, 2005; Lutz \& Lindell, 2008), or (b) whether they really do facilitate the high levels of organisational flexibility that may become necessary as incident complexity increases (DHS, 2008). That said, an early study conducted by Bigley and Roberts (2001) managed to identify 
a number of ICS factors that purportedly allowed a large US county fire department to respond reliably to dynamic unpredictable situations; and Lutz and Lindell (2008) also reported on activities within an Emergency Operations Centers (EOCs) during Hurricane Rita in 2005. Although Lutz and Lindell (2008) did not dispute Bigley and Roberts' (2001) findings, they nonetheless determined the implementation of ICS within the Texan EOCs 'left much to be desired' (p. 132).

The challenge with this study, funded through the Australasian Bushfire Co-operative Research Centre, is to investigate and better understand the extent to which the ICS approach to emergency incident management supports effective communication practices, information flow, and coordination, as well as the extent to which ICS enables and/or constrains the organisational flexibility that might be needed in volatile situations. The study reported here used a questionnaire method to obtain emergency management personnel perceptions about ICS in fire and emergency management of natural disaster events, and their satisfaction levels with the organisational principles underpinning ICS.

\section{Method}

The 2008 questionnaire included a number of questions that were the same as items included in a 2003 questionnaire conducted by the Australasian Fire Authorities Council (AFAC) as a precursor to the formal adoption of AIIMS as a national system in Australia. By including some of the 2003 questions, it was possible to make comparisons with the 2003 baseline data, which would provide insights into how the system had evolved over the past 5 years. Where appropriate, these comparisons are included in the findings.

In addition to providing baseline comparisons, the 2008 questionnaire was also developed to assess teamwork and communication processes and so help guide future policy decisions across the emergency management industry in Australia.

The items proposed were tested in three focus groups, with subject matter experts for validation in terms of its structure and content. In addition, key industry stakeholders (including AFAC representatives and key agency personnel) were emailed draft copies and asked to append comments and/or provide constructive critique. The final questionnaire was then reviewed by the national policy body, the AFAC-AIIMS Steering Group and endorsed for distribution.

Throughout the questionnaire (depending on the type of question), respondents were asked either to tick a box or boxes, or give a rating via 7-point Likert Scales (Burns, 2000). There were also a number of opportunities for respondents to give qualitative responses. The final version of the 2008 questionnaire was divided into six sections that sought information about types of incidents, levels of complexity, numbers of personnel involved, reporting pathways, areas of responsibility, phase of incident (e.g., initial, escalating), Incident Action Plans and other incident management issues, what helped/hindered people do their jobs, communication plans, resourcing and safety issues, availability of risk management tools, personnel proficiency, information management, use of technology, teamwork and interaction between the Incident Management Team and others involved in managing the incident (e.g., those working on the fire/incident ground), satisfaction with AIIMS/organisational procedures and processes, exposure to training and learning initiatives, and respondent demographics.

The questionnaire received ethics approval and an appropriate ethics information sheet, distribution plan, and copy of the questionnaire and associated instruction sheet were e-mailed to key personnel within agencies. The key personnel were asked to fill in the distribution plan for their particular agency and return the form. The purpose of the distribution plan was to identify how many people within each agency would be targeted to complete a questionnaire and to provide guidance to ensure the sample was stratified (Babbie, 2002; Burns, 2000). Those targeted included people who had worked in each of the Incident Management Team functional roles (i.e., Incident/Deputy Incident Controllers, and Planning, Operations, and Logistics personnel), as well as fire/incident ground personnel and those who had performed roles within coordination centres at either a state or regional level.

\section{Possible Limitations of the Study}

First, although the questionnaire has so far elicited 579 responses from people working within Incident Management Teams, combat roles and coordination centres across Australia and New Zealand, the overarching concern is that the sample might not be generalisable to the entire population of personnel involved in incident management. This is a potential problem for nearly all quantitative studies (Burns, 2000), most especially one like this that is attempting to capture an accurate snapshort of many thousands of people spread widely across a large geographic area. Steps were taken to try and mitigate this possibility with the 2008 questionnaire (e.g., via the dissemination of a distribution plan to assist in stratifying the sample) but the results should still be considered with this potential limitation in mind.

Second, by using third parties to disseminate the questionnaire it is not possible to know exactly how many people received the questionnaire and thus what the response rate is for every agency. Where known, however, the response rate varied between $10 \%$ and $100 \%$.

Third, it should be appreciated we were asking respondents to recall events that in some instances might have occurred several years previously. It is 
therefore possible there are inaccuracies in the data, simply because peoples' recollection of what happened was incomplete; for example, when they were asked to recall the contents of Incident Action Plans or what transpired at briefings. Again, this possibility was mitigated by adopting the same data gathering procedures as those used in 2003 by AFAC.

Finally, it would have been desirable in an article such as this to provide a cross-country comparision. However, since the numbers received from New Zealand agencies were small $(n=22)$, and since there were no obvious differences in responses evident, the database reported here is a combined one.

\section{The Sample}

The sample of 579 respondents provides a good stratification of personnel across the various layers of the ICS. As discussed, it is the work of the Incident Management Team that generates the main sources of information flow and actions in need of coordination, hence it was also important to get a good response rate from the various functional groups within the Incident Management Team. Table 1 shows that, of the 543 respondents who answered the question, 375 (65\%) personnel were in the Incident Management Team; 109 personnel (19\%) had a role on the incident ground or fire-ground, and 59 (10\%) were engaged in regional or state-level coordination. Of those engaged in the Incident Management Team, 112 (19\%) were in an Incident Controller/Deputy Incident Controller (IC/DIC) role; 96 (17\%) were in an Operations role; $107(18 \%)$ were in a Planning role; and $60(10 \%)$ were in a Logistics role.

Table 1 also shows the average number of years respondents had performed in their respective roles ( 9 to 13 years). The role of coordination, particularly at a regional level, is one that has only recently developed, and this is indicated in the proportion of respondents who had less than 5 years experience in their role (44\%), and in the average number of incidents (5) attended in that role. Table 1 also shows ICs/DICs had the most experience ( 13 incidents).

The questionnaire asked respondents to focus on one particular incident with which they were involved. The incidents reported included: grass/forest/scrub fires $(55 \%)$, including fires on the rural-urban interface (18\%); structure fires (9\%); cyclones, floods and storms $(15 \%)$. Nearly all of the incidents $(96 \%)$ were reported to have occurred in the past 3 years. Of the incidents, 37 (7.4\%) were Level 1, 110 (22\%) were Level 2, and 354 (70.5\%) were Level 3 incidents. A Level 3 incident is defined as one that is sufficiently complex to involve the full deployment of an ICS. That is, sectorisation of the fire or incident ground into divisions, each with their respective crews or teams of responders; a fully functioning Incident Management Team (with personnel in the differing functional units of Operations, Planning and Logistics) and, if there are multiple Incident Management Teams in place; establishment of a regional level of coordination, as well monitoring from a State Coordination Centre (AFAC, 2005). In terms of the sample of respondents in the functional areas listed above (see Table 1), there were no significant differences in the types of incidents reported, year of incident, or number of incidents previously attended.

\section{Findings}

Since the findings address the research questions raised earlier, this section is divided into three subsections. First, data are reported on the use of information flow practices supported within the ICS structures used in Australia and New Zealand. Next, respondent levels of satisfaction with these processes are outlined. Finally, indicators of how the system supports or constrains flexibility are discussed.

\section{Use of AllMS Practices}

While the questionnaire contained many items which sought details in relation to the processes that were used when an incident is being managed, only some will be reported here. These include: whether a briefing occurred and the nature of the content of the briefing, as well as information on the types of information tools (e.g., an Incident Action Plan) that were employed during the progress of the incident. Tables 2 to 4 show comparisons of these practices with the 2003 AFAC questionnaire data.

\section{Table 1}

Demographic Details of Respondents

\begin{tabular}{llccccc}
\hline & $N$ & $\%$ & $\begin{array}{c}\text { Mean years } \\
\text { exp. in role }\end{array}$ & $\begin{array}{c}\%<5 \text { years } \\
\text { exp. in role }\end{array}$ & $\begin{array}{c}\text { Ave. N of incidents } \\
\text { attended in role }\end{array}$ \\
\hline Incident Ground & Fire ground & 109 & 18.8 & 11 & 26.3 & 13 \\
Incident Management Team & IC/DIC & 112 & 19.3 & 13 & 24.3 & 15 \\
& Operations & 96 & 16.6 & 13 & 29.6 & 12 \\
& Planning & 107 & 18.5 & 8 & 38.4 & 11 \\
Coordination & Logistics & 60 & 10.4 & 9 & 44 & 8 \\
& Coordination & 59 & 10.2 & N/A & 42.9 & 5 \\
\hline
\end{tabular}


In 2003, 93\% of respondents stated they received a briefing, compared with $86 \%$ in 2008 . Of the $14 \%$ of respondents who did not receive a briefing in 2008, the majority were first on scene and/ or provided the briefing themselves.

Table 2 shows that the content of the briefing included many items suggested in emergency incident management policy (AFAC, 2005), and it can be observed that reference to certain types of briefing information had increased from 2003. A Chi-square test indicates a significant difference in the proportion of respondents who received information identifying current and expected resourcing. In 2008 this proportion was higher $(78 \%, n=363)$ than the proportion in the previous 2003 study $(49 \%, n=303), \chi^{2}(1, n=1080)$, = $88.29 p<.001$. In an emergency incident management context, it is clearly important to understand what resources are available and likely to be available in the future to help plan a response.

While these improvements are important, there is, however, an item of concern worthy of note. This is the apparent low level of information shared relating to identifying alternative strategies. As the Table shows, information on alternative strategies was provided 36\% of the time in 2008. One possible explanation could be that the data refers to incidents that were more straightforward and less complex. However, a cross-tabulation of responses by Incident levels reveals that this is not the case. Table 3 shows that there were just as many respondents who received advice about alternative strategies in briefings for Level 3 incidents as there were who did not.

Another critical source of information is the Incident Action Plan. In a Level 3 incident for example, an Incident Action Plan is prepared within the Incident Management Team and provided to the Divisional Commanders for dissemination to personnel on the incident or fire-ground. Its purpose is to set the strategy for the overall coordination of the incident management effort. The Incident Action Plan is also forwarded to regional and state levels of coordination to inform them about the overall operational decisions being taken.

\section{Table 2}

If a Briefing was Received, Did it Include ...

\begin{tabular}{|c|c|c|c|c|}
\hline Briefing items & $\begin{array}{c}2003 \\
N\end{array}$ & $\begin{array}{c}2003 \\
\%\end{array}$ & $\begin{array}{c}2008 \\
N\end{array}$ & $\begin{array}{c}2008 \\
\%\end{array}$ \\
\hline 'Explain what had happened so far' & 559 & 91.3 & 392 & 84.5 \\
\hline 'Explain the current situation' & 569 & 93.0 & 455 & 97.8 \\
\hline 'Outline objectives, strategies and rationale' & 473 & 68.6 & 376 & 80.5 \\
\hline 'Identify current and expected resourcing' * * & 303 & 49.5 & 363 & 78.3 \\
\hline 'Identify alternative strategies' & 148 & 24.2 & 170 & 36.8 \\
\hline 'Identify economic, social, public health and environmental risks' & 224 & 36.6 & 217 & 46.6 \\
\hline 'Identify key operation points' & 427 & 69.8 & 329 & 71.1 \\
\hline 'Identify boundaries of Sectors and Divisions' & 394 & 54.7 & 295 & 63.0 \\
\hline 'Outline the chain of command in the IMT' & 474 & 66.7 & 324 & 69.1 \\
\hline 'Identify location of IMT personnel' & 385 & 53.1 & 331 & 70.6 \\
\hline 'Provide info on the communications plan' & 371 & 60.6 & 285 & 60.5 \\
\hline 'Identify $\mathrm{OH} \& \mathrm{~S}$ issues' & 351 & 57.4 & 287 & 61.7 \\
\hline 'Define shift times' & 236 & 38.6 & 221 & 48.0 \\
\hline 'Utilise a SMEACS format' & NA & NA & 260 & 54.9 \\
\hline
\end{tabular}

\section{Table 3}

Alternative Strategies $\times$ Incident Complexity

\begin{tabular}{|c|c|c|c|c|c|}
\hline \multicolumn{2}{|c|}{ Identify alternate strategies } & \multicolumn{4}{|c|}{ Level of incident } \\
\hline & & \multirow{2}{*}{$\frac{\text { ICS Level } 1}{15}$} & \multirow{2}{*}{$\frac{\text { ICS Level } 2}{27}$} & \multirow{2}{*}{$\frac{\text { ICS Level } 3}{118}$} & \multirow{2}{*}{$\begin{array}{c}\text { Total } \\
160\end{array}$} \\
\hline Yes & Count & & & & \\
\hline & $\%$ within Incident level & 48.4 & 31.8 & 38.1 & 36.7 \\
\hline & Std. Residual & 1.0 & -.9 & .1 & \\
\hline \multirow[t]{3}{*}{ No } & Count & 16 & 58 & 192 & 266 \\
\hline & $\%$ within Incident level & 51.6 & 62.8 & 61.9 & 62.4 \\
\hline & Std. Residual & -.8 & .7 & -.1 & \\
\hline \multirow[t]{2}{*}{ Total } & Count & 31 & 85 & 310 & 426 \\
\hline & $\%$ within Incident level & 100.0 & 100.0 & 100.0 & 100.0 \\
\hline
\end{tabular}


In $2008,55 \%,(n=309)$ said they received an Incident Action Plan compared with $47 \%,(n=351)$ in 2003. There were also increases in the types of information reported (see Table 4), though none of these increases are statistically significant. Again, information on alternative strategies was given the lowest rating. It is also interesting to note the slight decline in information about the incident's predicted development, where 51\% ( $n=162$ ) said the Incident Action Plan contained this information in 2008 compared with 58\% $(n=204)$ in 2003 , though as stated, this is not statistically significant $\chi^{2}(1, n=670), 3.63=p<.057$.

\section{Satisfaction with AlIMS}

While the above findings indicate information flow using ICS practices are widespread, there are differences in levels of satisfaction across layers in the ICS with the organisational arrangements. In a Likert-type item to assess the effectiveness of the overall organisational framework, a Kruskal-Wallis Test showed there is a statistically significant difference in perceptions of effectiveness between the layers in the ICS (fire/incident ground, $n=$ 93; Incident Management Team, $n=335$; and Coordination, $n=51, \chi^{2}(2, n=479)=11.98, p=.003$. The median was 6 for all 3 groups. Mann Whitney $U$ tests between the layers in the ICS revealed that the significances discussed above occur between the fire/incident ground ( $M d=6, n=93)$ and the Incident Management Team $(M d=6, n=335), U=12559, z=-$ $3.00, p=.003, r=.11$ and between the Incident Management Team $(M d=6, n=335)$ and Coordination $(M d=6, n=51), U=6964, z=-2.23, p=.026, r=.15$; though the effect sizes are small.

Similarly, within the Incident Management Team there are also differences indicated within the Incident Management Team functional groups on both the extent to which the communication arrangements enabled you to do your job effectively and the effectiveness of the reporting relationships. A Kruskal-Wallis Test showed that there is a statistically significant difference for the effectiveness of reporting relationships within the Incident Management Team (IC/DIC, $n=102$; Operations, $n=84$; Planning, $n=$ 100 and Logistics, $\left.n=48 \chi^{2} 3, n=334\right)=11.02, p=.012$. The median was 6 for all four groups. The case was similar for support in perceptions of effectiveness of communication arrangements between members of the Incident Management Team: IC/DIC, $n=108$; Operations, $n=89$; Planning, $n=96$ and Logistics, $n=50$ $\chi^{2}(3, n=343)=18.86, p=.0005$. The median was 6 for IC/DICs and Operations and 5 for Planning and Logistics.

Mann Whitney $U$ tests between the functional units revealed that the significances discussed above occur between the IC/DIC group ( $M d=6, n=102)$ and the Planning Unit $(M d=6, n=100), U=3831, z=-3.22, p=$ $.001, r=.23$ for the effectiveness of reporting relationships. This is also the case for the effectiveness of communication arrangements where the IC/DIC group results were $(M d=$ 6, $n=108)$ and for the Planning Unit $(M d=5, n=96), U$ $=3538.5, z=-4.01, p=.0005, r=.28)$.

\section{Flexibility in Emergency Incident Management Organising}

Earlier in the article we raised the importance of having the capacity to be flexible in uncertain and dynamic conditions, but to what degree is this really necessary? In order to investigate this question more fully, Table 5 provides responses to an item aimed at assessing the extent to which personnel perceived there were factors that prevented them doing their job. It is interesting to note that in terms of the question Were there any factors that prevented you from doing your job? there were no significant differences between the ICS layers of fire/incidentground group, the Incident Management Team, and personnel in Coordination roles. However, a Chi-square test showed there were differences between functional units within the Incident Management Team in relation to this question (see Table 5). As the Table shows, it is the Planning Unit where the difference is most significant.

\section{Table 4}

Elements Included in the Incident Action Plan

\begin{tabular}{|c|c|c|c|c|c|}
\hline & & $\begin{array}{c}2003 \\
N\end{array}$ & $\begin{array}{c}2003 \\
\%\end{array}$ & $\begin{array}{c}2008 \\
N\end{array}$ & $\begin{array}{c}2008 \\
\%\end{array}$ \\
\hline a & Overall objectives & 327 & 93.2 & 302 & 94.8 \\
\hline $\mathrm{b}$ & Strategies for Divisions/Sectors & 286 & 81.5 & 273 & 86.4 \\
\hline$c$ & Information on alternative strategies & 190 & 54.1 & 159 & 50.8 \\
\hline$d$ & Resources allocated to Sectors/Divisions & 288 & 82.1 & 259 & 81.2 \\
\hline e & Site plan & 295 & 84.0 & 275 & 86.4 \\
\hline$f$ & Medical plan & 169 & 48.1 & 162 & 51.1 \\
\hline g & Information/contact details of agencies & 194 & 55.3 & 169 & 53.4 \\
\hline $\mathrm{h}$ & Communications plan & 277 & 78.9 & 265 & 82.8 \\
\hline $\mathrm{i}$ & Predictions of incident development & 204 & 58.1 & 162 & 51.1 \\
\hline j & Organisational chart & NA & NA & 182 & 57.6 \\
\hline k & Safety considerations & NA & NA & 262 & 82.5 \\
\hline
\end{tabular}


Although the Planning Unit accounted for only 29\% of the total sample, it accounted for $41 \%$ of the proportion of people in the Incident Management Team who said that there were factors that prevented them doing their job, $\chi^{2}(3), 14.687=p<.002$.

It is interesting to consider that in terms of the practices supporting information flow discussed earlier and the content of the Incident Action Plan, it is the Planning Unit which not only prepares the Plan but undertakes the work required to provide predictions of the progress of the incident. If personnel in the Planning Unit are confronting factors that prevent them doing their job effectively, then this is likely to have impacts on successful information flow and coordination across other layers in the ICS. As also identified earlier, there may be a range of systemic issues (such as the effectiveness of reporting relationships) that need to be addressed in order to improve perceived job effectiveness.

Another key question for consideration in this paper was how the various teams may work together to achieve the flexibility needed to manage in such challenging conditions. To this end, the questionnaire also included items aimed at assessing the capacity of teams to flexibly adjust their practices within the context of managing emergency incidents. The questionnaire asked respondents to think about the team they were working within and, on a scale of 1-7, express their level of agreement with the following statements:

- 'Strategies were adjusted in a timely manner as the incident unfolded.'

- 'Team members anticipated the needs of others.'

- 'Roles were effectively reallocated as the situation changed.'
Focussing specifically on the scores of personnel working within the Planning Unit, and in terms of whether respondents experienced factors that prevented them doing their job, there were differences in responses to the three identified team-based flexibility items. For example, respondents who answered 'yes' to the question of having factors that prevented them doing their job rated lower on the statement Strategies were adjusted in a timely manner as the situation unfolded $(M d=5, n=49)$ than those who said no to the question (No: $M d=6, n=$ 49), $U=666.0, z=-3.96, p=.0005, r=.40$. This was also the case for the team-based item Team members anticipated the needs of others, where Planning Unit respondents who stated that they did have factors preventing them doing their job rated significantly lower on this item (Yes: $M d=5, n=52$; No: $M d=6, n=48$ ), $U=$ 762.0, $z=-3.47, p=.001, r=.35$.

Similarly, personnel in the Planning Unit who had a higher score on the item roles were effectively reallocated as the situation changed also experienced less incidence of factors identified as preventing them doing their job: Yes $(M d=5, n=47)$, and No $(M d=6, n=42), U=598$, $z=-3.273, p=.001, r=.33$. This indicates that the flexibility required to respond to dynamic and unpredictable events is in part based on the practices within the team. Data for other members of the Incident Management Team as well as for different layers in the ICS followed a similar pattern but discussion of all layers and items are beyond the scope of this article.

\section{Discussion and Implications for Future Research}

This study set out to answer three questions in relation to the use of ICS in Australia and New Zealand and the

\section{Table 5}

Prevent Job by Functional Role Within the Incident Management Team

\begin{tabular}{|c|c|c|c|c|}
\hline \multicolumn{5}{|c|}{ Prevent job } \\
\hline & & Yes & No & Total \\
\hline \multirow[t]{3}{*}{ IC/DIC } & Count & 30 & 77 & 107 \\
\hline & $\%$ within prevent job & 23.3 & 34.5 & 30.4 \\
\hline & Std residual & -1.5 & 1.1 & \\
\hline \multirow[t]{3}{*}{ Operations } & Count & 27 & 62 & 89 \\
\hline & $\%$ within prevent job & 20.9 & 27.8 & 25.3 \\
\hline & Std residual & -1.0 & .7 & \\
\hline \multirow[t]{3}{*}{ Planning } & Count & 53 & 50 & 103 \\
\hline & $\%$ within prevent job & 41.1 & 22.4 & 29.3 \\
\hline & Std residual & 2.5 & -1.9 & \\
\hline \multirow[t]{3}{*}{ Logistics } & Count & 19 & 34 & 53 \\
\hline & $\%$ within prevent job & 14.5 & 15.2 & 15.1 \\
\hline & Std residual & .0 & .1 & \\
\hline \multirow[t]{2}{*}{ Total } & Count & 129 & 223 & 352 \\
\hline & $\%$ within prevent job & 100 & 100 & 100 \\
\hline
\end{tabular}


perceived levels of satisfaction among those who used the system.

The first research question was 'To what degree are the practices embedded within the ICS to support information flow and coordination being used by personnel engaged in emergency incident management, and in particular how have these evolved since 2003?' As noted earlier, this study reported on findings concerning the use of briefings and Incident Action Plans as exemplars. The reason for doing so was because briefings and Incident Action Plans are critical for disseminating information and for ensuring efficient coordination (both within and between agencies). It was therefore pleasing to find that their usage was generally widespread and had increased since 2003. As noted, however, briefings only identified alternative strategies $36 \%$ of the time in 2008 , while in terms of the types of information supplied in Incident Action Plans, two of the lowest ratings were given to the provision of information on alternative strategies, and predictions of incident development.

These findings raise two concerns that need to be addressed if improvements are to be made within an ICS. First is the need to ensure that there are practices supporting the capacity for contingency planning, given its importance in achieving consistently safe, high performance outcomes (Weick \& Sutcliffe, 2001). The second area that remains problematic is that of modeling the future development of an emergency incident, as well as providing appropriate information to those within the system about those possible developments. This is more likely to be an issue in dynamic, fastmoving and escalating events such as wildfires and less difficult in, say, a flood situation. Strategies to address this to improve ICS functioning are likely to include different components. New developments are needed to support future emergency modeling prediction. These may take the form of new technologies; and/or new strategies of organising for intelligence gathering and value-adding to this intelligence. In addition there may be a need to review reporting functions and authority to act, particularly under conditions of escalation that leads to the second research question.

The second research question was 'How satisfied are personnel with those [ICS] systems and are there any systemic areas of concern evident?' While there were good levels of support for the use of ICS practices (as exemplified by the widespread use of briefings and Incident Action Plans), there were notable differences in the levels of satisfaction across layers of the ICS with the organisational arrangements (i.e., between the Incident Management Team, fire/incident ground, and coordination centres).

In the initiative to establish AIIMS in Australia, one of the main objectives was to provide appropriate organisational structural support around the core unit of the system, the Incident Management Team. That this aim was at least partially met is supported by findings from this study (e.g., on the item asking about the effectiveness of the overall organisational framework, the median was 6 for those working within the IMT). However, the findings reported statistically significant differences between the various layers of the ICS on items relating to both the effectiveness of communication arrangements and the effectiveness of reporting relationships, where personnel working on the incident or fire-ground and in the levels of Coordination and were significantly less happy on these items than their counterparts in the Incident Management Team. These findings suggest it is important to move beyond a teamwork-only focus to better understand the communication and coordination issues between the Incident Management Team and incident/fire ground, and between the Incident Management Team and coordination centres.

Of course, this does not imply that the potential organisational issues confronting the Incident Management Team are any less important. The findings from this study also suggest there are still systemic issues within Incident Management Teams that are in need of further investigation - particularly in relation to perceived tensions in the reporting frameworks between Incident Management Team functional groups and the effectiveness of communication arrangements. As discussed, also of concern, is the issue of how the planning section actually goes about the business of predicting the future course of events. Again, our findings not only highlight that questions remain about how well the ICS supports the role and tasks of the planning section in particular, but raise the prospect of a need for future emergency management research to test the effectiveness of more finely honed intelligence-based data gathering techniques, as well as different levels of communication arrangements and reporting relationships.

With regard to the third and final question 'To what degree does the existing ICS enable the organisational flexibility needed in dynamic, unpredictable incidents?', it is the potential teamwork/organisational linkages and interdependencies that are perhaps most noteworthy. Our findings clearly demonstrate that when the various teams engage in teamwork practices that actively support organisational flexibility, they have manifestly fewer problems doing their job. This aspect of the study opens a number of important directions for future research.

For example, in related literature there have been few, if any, attempts to establish empirical links between the principles underpinning organising for high reliability (including approaches such as ICS) and high performance teamwork - although some theoretical connections have been proposed (Stanton, Baber \& Harris, 2008; Wilson, Burke, Priest \& Salas, 2005). The desirability of empirically linking the organisational functioning with team level functioning in the future should yield important benefits. These include first, 
identifying the types of teamwork indicators that are likely to support organising for high reliability (HRO) practices, and second, how people might learn and train effectively and so further enhance more consistently safe, high performance teamwork-based outcomes.

Finally, it is also important to better understand the organisational processes that are needed to support those teams who work in managing emergency events. In what ways might the system need to flex in order to support the people managing the incident? And conversely, what skills and attributes are needed in those personnel to be able to adapt and make the most of the resources they can bring to bear to manage in these conditions? What inhibits personnel and systems from successfully doing so? Given the current predictions of climate change and the increased likelihood of more extreme weather events (Hennessy, Macadam, \& Whetton, 2006), a better understanding of these sorts of ICS issues is critical for the future wellbeing of communities living in the Pacific and on the Rim.

\section{References}

Australasian Fire Authorities Council. (AFAC). (2005). The Australasian Inter-service Incident Management System: A management system for any emergency (4th ed.). Melbourne, Australia: AFAC Limited.

Babbie, E. (2002). The basics of social research (2nd ed.). Belmont, CA: Wadsworth/Thomson Learning.

Bigley, G.A., \& Roberts, K.H. (2001). The incident command system: High-reliability organising for complex and volatile task environments. Academy of Management Journal, 44(6), 1281-1299.

Burns, R.B. (2000). Introduction to research methods (4th ed.). Sydney, Australia: Pearson Education Australia.

Comfort, L., Ko, K., \& Zagorecki, A. (2004). Coordination in rapidly evolving disaster response systems. The American Behavioral Scientist, 48(3), 295-313.

Crichton, M.T., Lauche, K., \& Flin, R. (2005). Incident command skills in the management of an oil industry drilling incident: A case study. Journal of Contingencies and Crisis Management, 13, 116-128.
Department of Homeland Security (DHS). (2008). National Incident Management System. Available at http://www. fema.gov/pdf/emergency/nims/NIMS_core.pdf

Hennessy, K.J., Macadam, I., \& Whetton, P.H. (2006). CSIRO Marine and Atmospheric Research Report. Canberra, Australia: Australian Greenhouse Office.

Lutz, L.D., \& Lindell, M.K. (2008). Incident command system as a response model within emergency operation centers during Hurricane Rita. Journal of Contingencies and Crises Management, 16(3), 122-134.

Mendonca, D., \& Wallace, W.A. (2006). Impacts of the 2001 World Trade Center attack on New York City critical infrastructure. Journal of Infrastructure Systems. 12(4), 260-270.

Militello, L.G., Patterson, E.S., Bowman, L., \& Wears, R. (2007). Information flow during crisis management: Challenges to coordination in the emergency operations center, Cognition, Technology \& Work, 9, 25-31.

Moynihan, D.P., \& La Follette, R.P. (2007). From forest fires to Hurricane Katrina: Case studies of Incident Command Systems, IBM Center for The Business of Government: Madison.

Owen, C., Hickey, G., \& Douglas, J. (2008). Mapping information flow during critical incidents. Department of Sustainability and Environment, Victoria. Available at http://eprints.utas.edu.au/7855/

Stanton, N.A., Baber, C., \& Harris, D. (2008). Modelling command and control: Event analysis of systemic teamwork, Aldershot UK: Ashgate.

The 9/11 Commission. (2004). The 9/11 commission report. Available at http://www.9-11commission.gov/report/ 911Report.pdf

Weick, K.E., \& Sutcliffe, K.M. (2001). Managing the unexpected: Assuring high performance in an age of complexity. San Francisco: Jossey-Bass.

Wilson, K.A., Burke, C.S., Priest, H.A., \& Salas, E. (2005). Promoting health care safety through training high reliability teams. Quality and Safety in Health Care, 14, 303-309.

Wise, C.R. (2006). Organizing for homeland security after Katrina: Is adaptive management what's missing? Public Administration Review, May/June, 302-318. 